\title{
Information technology innovation diffusion: an information requirements paradigm
}

\author{
Nigel Melville* \& Ronald Ramirez ${ }^{\dagger}$ \\ *Stephen M. Ross School of Business, University of Michigan, Ann Arbor, MI 48109-1234, \\ USA, email: npmelv@umich.edu, and 'Business School, University of Colorado at Denver, \\ PO Box 173364, Campus Box 165, Denver, CO 80217-3364, USA, email: \\ ronald.ramirez@cudenver.edu
}

\begin{abstract}
Information technology (IT) innovation research examines the organizational and technological factors that determine IT adoption and diffusion, including firm size and scope, technological competency and expected benefits. We extend the literature by focusing on information requirements as a driver of IT innovation adoption and diffusion. Our framework of IT innovation diffusion incorporates three industry-level sources of information requirements: process complexity, clock speed and supply chain complexity. We apply the framework to US manufacturing industries using aggregate data of internet-based innovations and qualitative analysis of two industries: wood products and beverage manufacturing. Results show systematic patterns supporting the basic thesis of the information processing paradigm: higher IT innovation diffusion in industries with higher information processing requirements; the salience of downstream industry structure in the adoption of interorganizational systems; and the role of the location of information intensity in the supply chain in determining IT adoption and diffusion. Our study provides a new explanation for why certain industries were early and deep adopters of internet-based innovations while others were not: variation in information processing requirements.
\end{abstract}

Keywords: adoption, diffusion, information processing view, innovation

\section{INTRODUCTION}

The internet has changed the way firms conduct business, enabling new value creating activities and supporting enhanced collaboration with trading partners. However, the use of the internet and its related impacts vary widely across industries. In the personal computer (PC) manufacturing industry, for example, internet-based technologies have had wide-ranging 
impacts throughout the value chain, transforming competitive dynamics and generating new sources of value (Kraemer et al., 2000). In contrast, diffusion of these technologies has been modest in other industries such as textiles (Forza et al., 2000).

According to the dominant diffusion of innovation paradigm, technology characteristics, including trialability, observability, relative advantage, complexity and compatibility might provide an explanation for such differences (Rogers, 1983). However, focusing on technology characteristics provides only a partial explanation for industry variation because similar types of information technologies (IT) are available to all firms and are readily implemented by a burgeoning IT consultancy industry. Another explanation provided by the dominant paradigm is technology adopter characteristics, such as firm size and scope, technology leadership, technology competency, readiness and expected benefits (Rogers, 1983). Indeed, empirical research shows the influence of such organizational characteristics on innovation adoption (Mustonen-Ollila \& Lyytinen, 2003). Given substantial intraindustry firm variation along these dimensions (Chwelos et al., 2001; Macher et al., 2002; Zhu et al., 2004), this explanation is also incomplete. Moving beyond the dominant paradigm, the competitive environment, including competitive pressure and industry standards, may also play a role in technology diffusion and adoption (Tornatzky \& Fleischer, 1990). In sum, although the dominant paradigm and extensions may provide some insight into observed variation in internet adoption across industries, it is not clear to what extent these or other factors may explain such differences.

Reviewing the IT innovation literature, Fichman (2004) concludes that most studies have used economic-rationalistic models, an organizational level of analysis, and a logic that organizations possessing a greater amount of the right stuff will display a greater amount of innovation. Such a focus has yielded substantial insight, but has also constrained modalities of inquiry, and by extension, understanding of core phenomena. According to Fichman (2004), 'IT innovation researchers must also occasionally question fundamental assumptions and seek out more radical concepts and methods to reinvigorate the field.' In this vein, studying industry-level phenomena holds great potential to provide new insight into IT innovation adoption (King et al., 1994; Crowston \& Myers, 2004).

We move beyond the dominant paradigm of IT innovation literature by examining IT innovation from an information processing perspective. The production process, supply chain and competitive environment vary substantially across industries, creating differing information processing needs. According to the information processing view, enhancement of a firm's information processing capabilities is a viable response to such information challenges and can be achieved through investments in technology-based process improvements. It would thus seem reasonable to posit that industry-level characteristics are associated with variation in IT-based innovation adoption. For example, the home building industry has not widely adopted IT and internet-enabled business practices. It is a fragmented industry, highly labour intensive, and thus not amenable to mass production methods. However, the emerging modular home segment uses mass-production processes to manufacture walls, roofs, etc., which are then trucked to home sites and assembled onsite. Relative to mainstream home building, this segment of the industry is a considerable user of IT and the internet. One possible explanation is that alternative methods of production and supply chain management require 
different uses of information, which are enabled by different types of IT. The dominant paradigm, with its focus on technological and organizational characteristics, would be limited in explanatory power in this context. As a first step contributing to understanding in this area, we undertake an analysis within the manufacturing sector. Our fundamental research question is: How do information processing requirements determine the adoption and diffusion of IT innovation across industries?

The structure of the paper is as follows. We begin by describing the theoretical antecedents of the information requirements paradigm of IT innovation diffusion, including diffusion theory and the information processing view of the firm. Next, we develop a conceptual framework linking information processing requirements to information processing capabilities. We then apply the framework as a tool to interpret empirical data on US internet-based innovation adoption and alternative innovation profiles of two contrasting industries: wood products and beverage manufacture. In doing so, we show the validity of the framework and extend knowledge of how information processing requirements shape IT innovation adoption and diffusion. The last section describes implications for research and practice and identifies limitations of the study.

\section{THEORETICAL BACKGROUND}

\section{Diffusion theory}

Three stages of diffusion theory can be identified in the literature: dominant, technologyorganization-environment and emergent. According to the dominant paradigm, the rate and pattern of the adoption and diffusion of ideas, practices or objects through populations of potential adopters is affected by the characteristics of both the innovation and the adopter (Rogers, 1983). The multistage adoption process is affected by the actions of 'key adopters', the resulting profile being characterized by an S-shaped curve. Information systems (IS) researchers have applied the dominant paradigm to examine a variety of IT-based innovations, including electronic scanners in supermarket chains (Zmud \& Apple, 1992), spreadsheet software (Brancheau \& Wetherbe, 1990), IT outsourcing (Loh \& Venkatraman, 1992), and internet computing (Lyytinen \& Rose, 2003). Examining this literature, Swanson (1994) concludes that firm-level effects are salient in explaining the adoption and diffusion of IS innovations. A drawback of the dominant paradigm, however, is its narrow focus on only two innovation drivers, namely, technology and organizational factors.

The dominant paradigm was extended by Tornatzky \& Fleischer (1990), who added the external environment as another factor driving adoption and diffusion of innovations. In the context of internet-based innovations, this extension suggests that organization-level factors, technology factors, as well as the firm's external environment all impact the diffusion process. Zhu et al. (2004) test this framework by analysing innovations associated with the electronic pre-processing, negotiation, performance and post processing of business transactions among firms via the internet. The authors find that internal factors - technology competence and firm 
scope and size - and external factors - consumer readiness and competitive pressure - are significant adoption drivers, providing support for the inclusion of external factors in studies of IT innovation diffusion. However, despite its expanded focus, application of the technologyorganization-environment paradigm remains limited in the IS context as it largely ignores the primary function of IT, i.e. processing, storing and capturing information.

Finally, in the emergent stage of diffusion theory, Fichman (2004) suggests seven 'promising opportunities' to extend the dominant paradigm: contagion effects, management fashion, innovation mindfulness, innovation configurations, technology destiny, quality of innovation, and the performance impacts of innovative IT. Several of these approaches offer the potential of extending and refining our understanding of IT innovation diffusion from an industry perspective. As an example, social contagion may be an important factor among firms within a single industry. Firms may be more likely to be affected by other firms in their industry who have already adopted an IT innovation.

Although the dominant paradigm, technology-organization-environment extension and emergent stages of diffusion theory have improved understanding of the antecedents of IT adoption and diffusion, they do not explicitly address the role of information processing requirements. We thus extend our focus to move beyond diffusion theory, consistent with the suggestion of Cooper \& Zmud (1992, p. 137) that studies will be improved if they 'adequately account for the "fit" between the technology being examined and the work context within which the technology is being introduced.' We adopt the information processing view of the firm to shed light on the connection between information processing requirements across industries and the adoption and diffusion of IT innovations.

\section{Information processing view}

The information processing view provides an alternative rationale as to why firms adopt IT innovations: to respond to information processing requirements. According to the information processing view, organizations can be viewed as information processing systems that develop information processing mechanisms to deal with environmental sources of uncertainty (March \& Simon, 1958; Galbraith, 1977; Tushman \& Nadler, 1978; Van de Ven \& Ferry, 1980). Given imperfect knowledge and imprecise decision-making, firms develop patterns and routines of behaviour to complete individual organizational tasks. When changes in the environment occur, they give rise to uncertainty, as established routines can no longer be used. Firms face new information requirements as additional information must now be collected, processed and distributed in order for the firm to make decisions and complete its activities. To continue to operate efficiently, a firm must align its information processing capabilities with its new information requirements. The firm responds to complexity by either increasing its information processing capabilities or by reducing its information processing needs (Galbraith, 1977). System effectiveness is contingent upon the degree of fit between system and requirements, and organization scholars have found empirical associations between complexity and information processing modes (Tushman \& Nadler, 1978; Van de Ven \& Ferry, 1980). 
IS scholars have used the information processing view to explore the relationship between IS and information requirements. Anandarajan \& Arinze (1998) examine the extent to which a client/server IS architecture matches contextual information needs. Using survey data from 89 client/server implementations, the authors find that efficiency is a function of the fit between task characteristics - task analysability and task interdependence - to the client/server architecture - client- vs. server-centric. Indeed, the overall performance of a firm is associated with how well a firm matches the information processing requirements it faces with the degree of alignment between the role of IS, centralization of IS and the formalization of IS (Wang, 2003). The information processing view has also informed analysis of environmental uncertainty and task characteristics in the context of user satisfaction with data (Karimi et al., 2004).

Existing research shows that information processing capabilities adopted in response to information processing requirements can vary. An examination of the US and Japanese automobile industries uncovers five configurations of interorganizational relationships between buyers and suppliers (Bensaou \& Venkatraman, 1995). In one configuration - electronic interdependence - the authors found that in the case of highly customized and complex products, firms tend to be significant users of electronic communications tools as well as traditional means as a response to substantial environmental uncertainty. The authors conclude that there may be several ways to design interorganizational relationships that are equally effective. Similarly, variation in response has been identified in an investigation of production maintenance operations. Specifically, maintenance operations respond to complexity by using various combinations of computerized maintenance management systems, preventive and predictive maintenance systems, coordination and workforce size (Swanson, 2003).

The information processing view in the IS context is also supported by studies of organizational response to industry clock speed (Mendelson \& Pillai, 1998; 1999). In a study of manufacturers of computers and related products, for example, Mendelson \& Pillai (1998) adopt the view that information processing requirements underlie the adoption and diffusion of communication technologies. In highly dynamic business environments, firms must adopt new ways of processing increased volumes of information, with IT being a major enabler of such processing. Results support the information processing view of the firm in that higher clock speed environments are associated with greater use of IT by firms.

In sum, the information processing view is useful in the context of IT-based innovation as it provides an alternative perspective of why firms adopt such innovations. Internal and environmental uncertainty, whether based in production methods, supply chains or the larger competitive landscape, gives rise to new information requirements - a key driver of firm adoption of information technologies. We now develop a conceptual framework of IT-based innovation based on the information requirements paradigm.

\section{CONCEPTUAL FRAMEWORK}

The conceptual framework is developed to shed light on our primary research question, which asks how information processing requirements shape the adoption and diffusion of IT across 
industries. The basic thesis is that within an industry, common means of production, supply chains, and a shared competitive landscape provide common information requirements for firms within that industry, leading to incentives to adopt IT innovations. As an example, firms in industries with short product life cycles and rapid product innovation are characterized by a high degree of uncertainty, leading to substantial information processing requirements. Firms may turn to various forms of IT as a means of providing the information processing capacity necessary for rapid product development and market introduction. In contrast, all else being equal, we might expect industries with longer product life cycles to be subject to less stringent information processing requirements, resulting in lower IT adoption. We build on prior research by developing a conceptual framework that includes information processing requirements (process complexity, clock speed and supply chain complexity) and information processing capabilities (production systems and interorganizational systems) (Galbraith, 1977; Tushman \& Nadler, 1978; Bensaou \& Venkatraman, 1995; Mendelson \& Pillai, 1998).

Information processing requirements arise from the gap between information required and information available, i.e. uncertainty. Three sources of uncertainty are (1) task complexity and subunit task interdependence; (2) task environment; and (3) interunit task interdependence (Tushman \& Nadler, 1978). The framework is intended to represent interdependencies between the three task characteristics: uncertainty, fit and information processing requirements. We adapt the three sources of uncertainty used in the original framework as follows. To match our approach of analysing IT innovations across industries, we include process complexity to reflect the focus of modern firms on business processes and provide a contemporary construct encompassing the original task construct. The second dimension - clock speed encompasses the rate of environmental change that was included in the original framework and is adopted from prior IS research (Mendelson \& Pillai, 1998). The third dimension is supply chain complexity, which extends the idea of external interdependence of tasks to the contemporary business environment of complex, global supply chains. Regarding information processing capabilities, we focus on salient categories of IS used in the manufacturing environment: IT-based production control and supply chain management systems. (As our focus is not on other information processing mechanisms, such as meetings and site visits, we do not include them in our framework.) We model the five measures as formative indicators of their respective constructs, as the direction of causality flows from measure to construct and the measures do not necessarily covary (Jarvis et al., 2003) (Figure 1).

\section{Information processing requirements}

\section{Process complexity}

Process complexity includes a variety of factors associated with the production process that give rise to uncertainty (Table 1). First is product variety, which denotes the number of parts, models, brands, etc. High product variety raises complexity and uncertainty due to multiple interrelated demand signals (Prasad, 1998). Related to the type of product being produced, the second process complexity factor - production method - includes job shop, flow, continuous 
Information Processing

Requirements

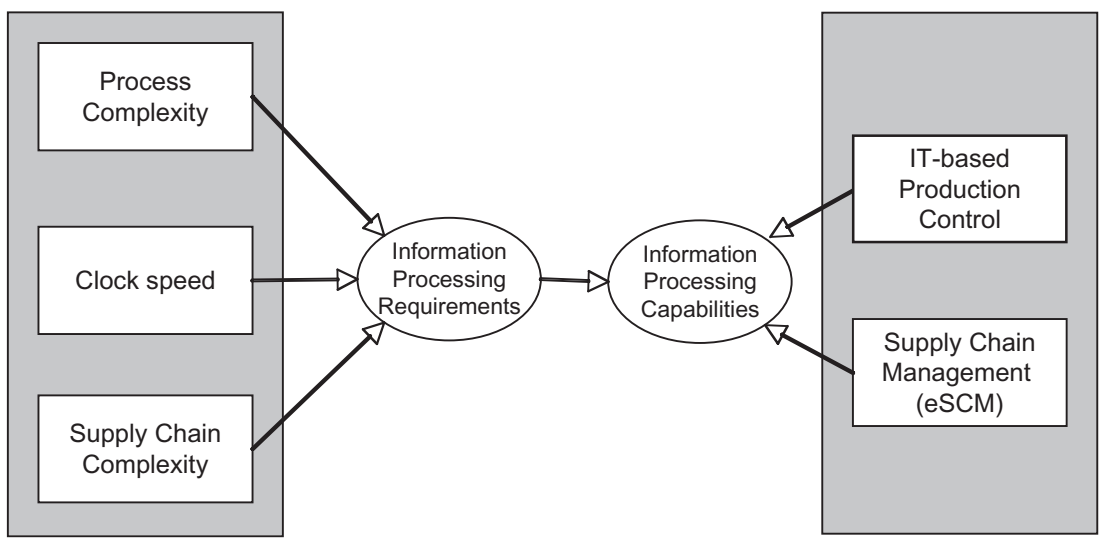

Figure 1. Information processing requirements paradigm of IT innovation diffusion. Note: Adapted from Tushman \& Nadler (1978). Ellipses represent latent constructs, boxes represent indicators, and arrow directionality indicates formative indicators.

Table 1. Information processing requirements paradigm: key constructs

\begin{tabular}{|c|c|}
\hline \multicolumn{2}{|c|}{ Information processing requirements } \\
\hline Process complexity & $\begin{array}{l}\text { Complexity associated with the production process: product variety, production } \\
\text { method, information intensity. }\end{array}$ \\
\hline Clock speed & $\begin{array}{l}\text { Degree of dynamism or change in an industry, as measured by the speed at } \\
\text { which new products, processes and organizational structures are introduced. } \\
\text { Driven by endogenous industry factors such as competition } \\
\text { and technological change. }\end{array}$ \\
\hline Supply chain complexity & $\begin{array}{l}\text { Processes associated with and characteristics of the supply chain: informational } \\
\text { and product span across physical and logical spaces and nature of } \\
\text { interactions between upstream suppliers and downstream buyers. }\end{array}$ \\
\hline
\end{tabular}

Information processing capabilities

IT-based production control

Mainframe, minicomputer, and PC-based systems that enable multiple production control functions including, among others, product testing, flow control and analytics.

Supply chain management (eSCM) Interorganizational systems, including electronic data interchange (EDI) and Internet-based systems, that enable collaboration and exchange with trading partners: procurement, sales, online selling, information sharing, collaborative design, online specification sheets, online auctions, ERP, etc.

processing and assembly, each showing alternative levels of process complexity (Woodward, 1994). In some industries products are made to stock, whereas in others, production is driven by demand pull. The latter requires a greater degree of information processing capabilities in order to capture and act upon dynamic demand signals. The third process complexity dimen- 
sion is information intensity of the production process, including the volume of information required for quality control steps, physical tolerances, etc.

\section{Clock speed}

Clock speed denotes the speed of industry evolution, including the rate at which new products, processes and organizational structures are introduced (Fine, 2000). Resulting from endogenous industry factors such as competition and technological change, specific measures include the duration of product life cycles and the rate of decline in the prices of input materials (Mendelson \& Pillai, 1998). Firms in high-clock speed industries face extremely short design and production horizons, as well as severe pressure on inventory (Fine, 1998). Many well-known cases of internet-based innovation appear in high-clock speed industries such as microprocessors (Phan, 2003) and data routers (Kraemer \& Dedrick, 2002). In an industry such as PC manufacturing with rapidly declining prices, controlling inventory costs is a key to success, and internet-based technologies are used to manage supply chains using build-to-order and online sales (Kraemer et al., 2000). In the IT products industry, increased clock speed is positively associated with the use of various communication technologies such as electronic data interchange (EDI), further supporting its inclusion in the framework (Mendelson \& Pillai, 1998).

\section{Supply chain complexity}

Supply chain complexity denotes the degree of coordination required across firm boundaries. This includes the informational and product span across physical and logical spaces as well as the nature of interactions between upstream suppliers and downstream buyers. For example, the apparel industry is characterized by a global end-to-end supply chain of design, production and distribution (Teng \& Jaramillo, 2005). In contrast, wood products tend to be processed near the source of raw materials (forests), and then trucked or shipped to plants that use processed timber as an input (e.g. home builders). Such a difference in the geographic dispersion of information and production associated with supply chain processes presents alternative needs for the use of interorganizational IS, including both traditional EDI as well as web-based interorganizational IS. Also salient is the institutional structure of the demand channel, which, if highly concentrated, may afford bargaining power to pressure upstream firms to adopt IT innovations.

\section{Information processing capabilities}

\section{IT-based production control}

Computers and networks are an integral part of the manufacturing production process. Mainframe, minicomputer and PC-based systems enable computer-aided design and computeraided manufacturing (CAD/CAM). System functionality includes analytic applications used in forecasting, scheduling and other operations management functions as well as digital sche- 
matic representation and manipulation. An auto manufacturing plant, for example, may use programmable logic controllers and distributed control systems to collect sensory data, check it against control parameters, and send feedback signals to production machine tools. A PC-based production system may also use analytic software for forecasting and scheduling. Given variation in demand dynamics and process complexity across industries, we expect that different forms of production control are used across industries.

\section{Supply chain management}

EDI is an industry standard method of communicating electronic documents, such as purchase orders and invoices, via proprietary value added networks. In recent years, the internet and its open standards has emerged as a platform of choice for communication and exchange across the supply chain, subsuming EDI functionality and adding an array of real-time collaboration and exchange functions (Johnson \& Whang, 2002). Exchange includes procurement and selling between supply chain partners (auctions, electronic catalogues, etc.) as well as associated supply chain processes, such as sending an invoice electronically to a customer or online customer support. Collaboration involves nonexchange related interfirm cooperation such as online design spaces, online meeting spaces, etc., between supply chain partners. Internet-based exchange and collaboration also support global supply chains such as those found in the electronics manufacturing industry. Extranets, for example, enable trading partners to access portions of internal data, thereby increasing information processing capabilities (Fowler et al., 2000). Another example is online vendor-managed inventory, which improves supply chain efficiencies by placing the responsibility of managing inventory in the hands of the stakeholder that is in control of logistics, typically the supplier. Real-time customer inventory data are communicated back to the supplier so that accurate decisions can be made regarding supplier-related manufacturing schedules and finished goods stock levels. There is wide variation in such internet-based innovation across industries, with empirical evidence suggesting an informational basis for such variation (Cagliano et al., 2003).

\section{ANALYSIS}

As reviewed above, prior research has not focused on examining how information processing requirements shape the adoption and diffusion of IT innovations across industries. We are thus faced with several research hurdles, including a lack of applicable prior research on which to build, as well as an emergent and inherently complex phenomenon. Moreover, the majority of studies analysing internet-based innovations have been conducted in high-tech industries, leaving uncertainty as to what is happening in other industries. Based on these considerations, we have chosen to apply our framework using descriptive industry data analysis and focused industry studies. 
We conduct descriptive data analysis of 21 North American Industry Classification System (NAICS) industries and qualitative analysis of two industries: wood products and beverage manufacturing. While the former grounds our perspective in aggregate empirical observation, the latter provides a rich tableau of the variation in information processing requirements and information processing capabilities across two varying industries. Cross-industry analysis is important for uncovering phenomena that may be localized to a particular industry and have not been exposed in prior industry research (Chiasson \& Davidson, 2005). Indeed, our selection of industries provides such an opportunity as a majority of industry-related research examines manufacturing, high-technology, and finance, real estate, and insurance industries. (In their examination of research published in MIS Quarterly and Information Systems Research between 1997 and 2004, Chiasson \& Davidson (2005) find that of all articles that draw data from a particular industry, $71 \%$ do so from these three industries.) Industry-level analysis is also appropriate in situations where the industry can be affected by variations in how firms adopt and implement new technologies (Wigand et al., 2005). Finally, industry analysis in which the analysis unit is the industrial production environment is appropriate for analysing emergent phenomena, especially when the boundaries between phenomena and context are not clearly evident (Mendelson \& Pillai, 1998; Cagliano et al., 2003). Such is the case in Wigand et al.'s (2005) study of the effect of new XML-based standards for interorganizational coordination in the US home mortgage industry. In sum, the advantage of our analysis approach is that it provides richness and scope, while the key limitation is the lack of formal statistical analysis.

\section{Aggregate US industry data}

We examine industry-level data to provide insight into how internet-based innovation adoption and diffusion vary across industries due to variation in information processing requirements. According to our thesis, we would expect a wide variation in such processes across industries. Although few data sources and little prior research has been carried out, there is a database collected by the US Census Bureau at the NAICS industry level. The data do not allow for empirical analysis at the firm level as published data comprise tabulations of NAICS industries. Further, they do not enable formal statistical analysis, as there are only 21 three-digit NAICS industries. However, they do provide a unique lens into the use of internet business processes across roughly 30000 US manufacturing firms in 21 industries for the year 2000.

Five technologies that underlie internet-based innovation are intranets, the internet, local area networks (LAN), EDI and extranets. Based on our developed conceptual framework, we might expect a greater percentage of firms in industries characterized by a high degree of process complexity, rapid clock speed, and high supply chain complexity to use these technologies. To examine whether this might be the case, we tally the number of instances in which a given industry appears in the top five or bottom five in terms of percentage of plants using these five technologies (Table 2).

Electrical equipment and transportation equipment are in the top five in every technology category in terms of rank ordered percentage of using plants in the industry. Next are computer and electronic products (four times in top five), paper and primary metals (three times), 
Table 2. Percentage of manufacturing plants by industry adopting five internet-based innovations: rank ordered

\begin{tabular}{|c|c|c|c|c|c|}
\hline $\begin{array}{l}\text { Number } \\
\text { of times } \\
\text { appearing }\end{array}$ & 5 & 4 & 3 & 2 & 1 \\
\hline \multirow[t]{2}{*}{ Top 5} & $\begin{array}{l}\text { Electrical equipment, } \\
\text { appliances, and } \\
\text { components }\end{array}$ & $\begin{array}{l}\text { Computer and } \\
\text { electronic } \\
\text { products }\end{array}$ & Paper & Machinery & Apparel \\
\hline & $\begin{array}{l}\text { Transportation } \\
\text { equipment }\end{array}$ & & Primary metals & Chemicals & \\
\hline \multirow[t]{2}{*}{ Bottom 5} & Wood products & Apparel & $\begin{array}{l}\text { Textile product } \\
\text { mills }\end{array}$ & $\begin{array}{l}\text { Leather and } \\
\text { allied products }\end{array}$ & $\begin{array}{c}\text { Printing and related } \\
\text { support activities }\end{array}$ \\
\hline & & $\begin{array}{l}\text { Petroleum and } \\
\text { coal products }\end{array}$ & $\begin{array}{l}\text { Furniture and } \\
\text { related products }\end{array}$ & & \\
\hline
\end{tabular}

Source: Tehan (2003).

Note: Technologies include intranets, Internet, LAN, EDI and extranets. Cells derived by rank ordering industries by percentage of plants using each of five technologies. For example, first cell means that two industries - electrical equipment, appliances, and components, and transportation equipment - appeared within the top five by percentage of plants using for each and every technology. By contrast, wood products is in the bottom five of the rank ordered list for each and every technology.

machinery and chemicals (twice), and apparel (one time). Electrical equipment and transportation production are characterized by high degrees of process complexity and supply chain complexity, as global supply chains are used to manage parts procurement and demand fulfilment. This is also the case for computer products, with the added factor of a very high clock speed. Thus, at least based on these descriptives, the use of internet-based innovation by these three industries appears to be consistent with the developed conceptual framework. On the other end of the scale are wood products, apparel and petroleum and coal products. Both wood and petroleum are not characterized by rapid product evolution, and thus have lower clock speeds. Moreover, process steps are fewer and global supply chains are not as complex as other industries. Descriptive statistics are thus consistent with the information requirements paradigm. An anomaly is apparel, which is in the top five one time (EDI) and in the bottom five for the remaining four categories. This is difficult to explain without more detailed and extensive analysis.

Another perspective on internet-based innovation is to move beyond technologies and examine functionality of innovations. Figure 2 displays five basic processes - email with trading partners, internet buying, EDI buying, internet selling, EDI selling - according to the percentage of using plants (lowest industry, median, highest industry). Internet use and EDI use are included to provide a baseline comparison. The data indicate that three industries account for the highest percentage of plants using these processes: computer and electronics, transportation, and printing and related. The first two are consistent with data on technology usage presented in Table 2. Industries with the lowest percentage of adopting plants include petroleum and coal, wood, non-metallic metals, textile mills, and printing and related. Once again, we see clear consistency with these industries and those that adopt technologies slowly. An anomaly is printing, which is highest in internet buying and lowest in internet selling. 


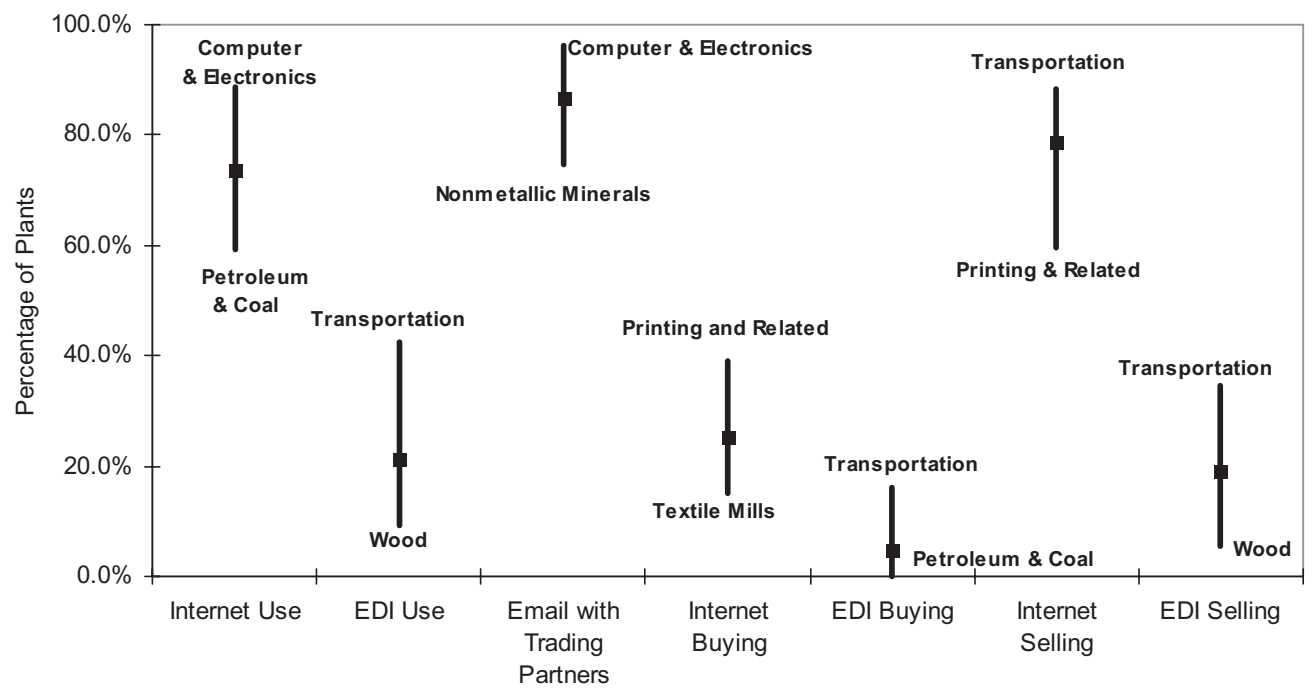

Figure 2. Percentage of manufacturing plants adopting e-business innovations by industry: rank ordered. Source: Tehan (2003). Note: Industry names provided for highest and lowest categories, i.e. those with the highest percentage of plants in each particular category as well as the lowest. Median percentage is indicated by the square.

Although preliminary and subject to firm-level empirical testing, exploratory analysis of industry-level data appear to be consistent with our thesis that information processing requirements are an important factor in the extent to which industries adopt internet-based innovation. To examine this hypothesis further, we examine one industry at the low end of the usage scale - wood products - and one in the middle - beverage manufacture. We do not examine highly innovative industries as these have been studied extensively in prior research.

\section{Industry application: wood products and beverage manufacturing}

Data for the industry analyses were gathered through a variety of sources. First, we used research databases to identify pertinent industry reports and published research involving any aspect of computerization or supply chain management. Second, we examined company reports, such as $10 \mathrm{~K}$ documents, of firms within the two selected industries. Third, we examined newspaper articles and government data on internet business practices. The resulting corpus of material provided a substantial amount of raw data enabling analysis of each construct in the conceptual framework in great detail.

We apply the conceptual framework within two industries to show its applicability and to inform our fundamental research question. Several case studies exist of firms in industries with high degrees of all three dimensions of information processing requirements. Not surprisingly, in these industries it is found that internet-based innovation is abundant. In contrast, we sought low-tech industries with moderate and low degrees of information processing requirements. To 
provide the necessary variation in information processing requirements, we sought variation in both manufacturing processes (process complexity) and the interfaces between suppliers and customers (supply chain complexity). We chose wood products (NAICS 321) as it is consistently ranked in the bottom of internet-based innovations in Census Bureau data and beverage manufacturing (NAICS 3121) as it is consistently in the middle range.

\section{Wood product manufacturing}

Wood product manufacturers produce wood products such as lumber, plywood, veneers, wood containers, wood flooring, wood trusses, manufactured homes, and prefabricated wood buildings. On the demand side, buyers of industry output use processed lumber for furniture, home construction, cabinets, flooring, and the like. In the primary segment, lumber, plywood and particle board are sourced to sales distribution channels including wholesalers, distributors, brokers and retail stores. On the supply side, upstream is the logging process, which includes forest harvesting, sorting and handling. A simplified schematic of the wood product manufacturing supply chain is shown in Figure 3 a.

\section{- Information processing requirements: process complexity}

The multistage process of creating wood products from raw timber begins with the scanning of a raw roundwood piece of lumber for the existence of unwanted foreign material that could adversely affect the production process (Araman et al., 1992). After the scan, the log is

3a. Wood Products

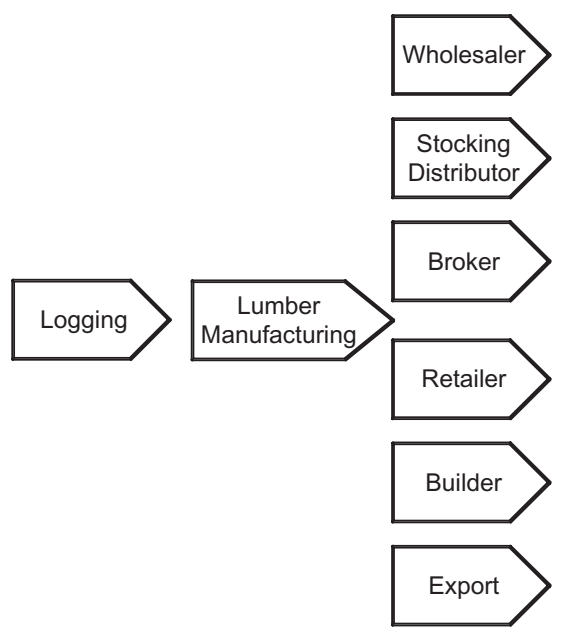

3b. Beverages

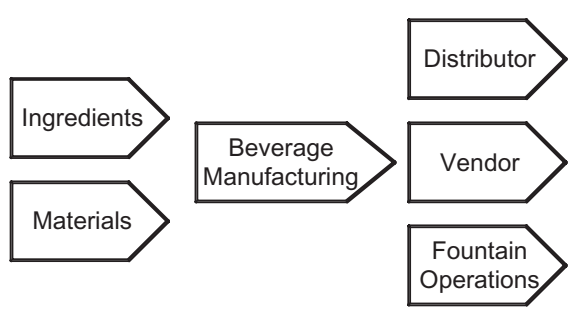

Figure 3. Wood products and beverages supply chains: simplified schematic. 
debarked, graded for quality, and an individualized production plan is developed to maximize the log's processed value. A band hedger creates boards from the log according to plan and the boards are trimmed and then kilned to remove moisture. After drying, the boards are planed, graded and stacked for delivery to customers (Table 3). (This manufacturing process is used throughout the industry, for example, by Ward Lumber, a typical lumber manufacturer located in New York State. http://www.wardlumber.com/) Other than the size and grade of the finished board, there is a low degree of product variety. Moreover, there are relatively few production stages: scan, prep, cut and trim, kiln, finish.

From an information perspective, when a piece of raw roundwood lumber is scanned before edging, information is collected on defects, the amount of clear wood, and potential board cutting plans. This information is used to determine standard products that can be generated from each log, to grade the lumber according to industry standards, and to determine the best cutting plan for the maximization of finished product value (Araman et al., 1992). While the cutting of each log is relatively straightforward, uncertainty regarding individual log shape, size and quality requires the development of production processes that take into account nonstandardized inputs. There is a specialized front-end process that necessitates the creation of dynamic production plans for each log entering the lumber mill. In sum, process complexity is low compared with other industries.

\section{- Information processing requirements: clock speed}

There is a relatively low rate of change in the types of wood products demanded by downstream buyers as well as in the upstream wood procurement inputs. Moreover, processes and organizational structures are fairly stable (Vlosky \& Smith, 2003). Wood products are intermediate goods used in the creation of homes, furniture and other end products. Consumer preference changes are reflected in the manufacturing of these finished goods rather than the output of lumber mills. In addition, while technology such as geographic IS is sometimes used to manage timber inventory and yields, lumber inputs (logs) themselves do not have embedded technologies. As such, there is extremely low technological innovation and pressure in the upstream supply of logs as well as in the downstream demand for lumber. In sum, the stability of lumber preferences and technology advancement suggests a relatively low clock speed relative to other industries.

Regarding competitive pressure, lumber plants vary in size depending upon which of the two major categories of wood they manufacture: softwood or hardwood. While the softwood lumber industry is concentrated with larger firms operating at a larger scale, the hardwood lumber industry is relatively fragmented, with companies employing less than 20 workers (Vlosky \& Smith, 2003). The size of these firms puts a damper on capital asset and technology investments due to skill and resource limitations. Regardless, all sectors in the lumber industry are facing increased environmental pressures. Manufacturers face increased competition from global firms, especially those from the Canadian softwoods industry. In fact, increased price pressure and potential job losses in the wood products industry contributed to the implementation of antidumping tariffs on Canadian wood imports into the USA (Koppel, 2004). Lumber 


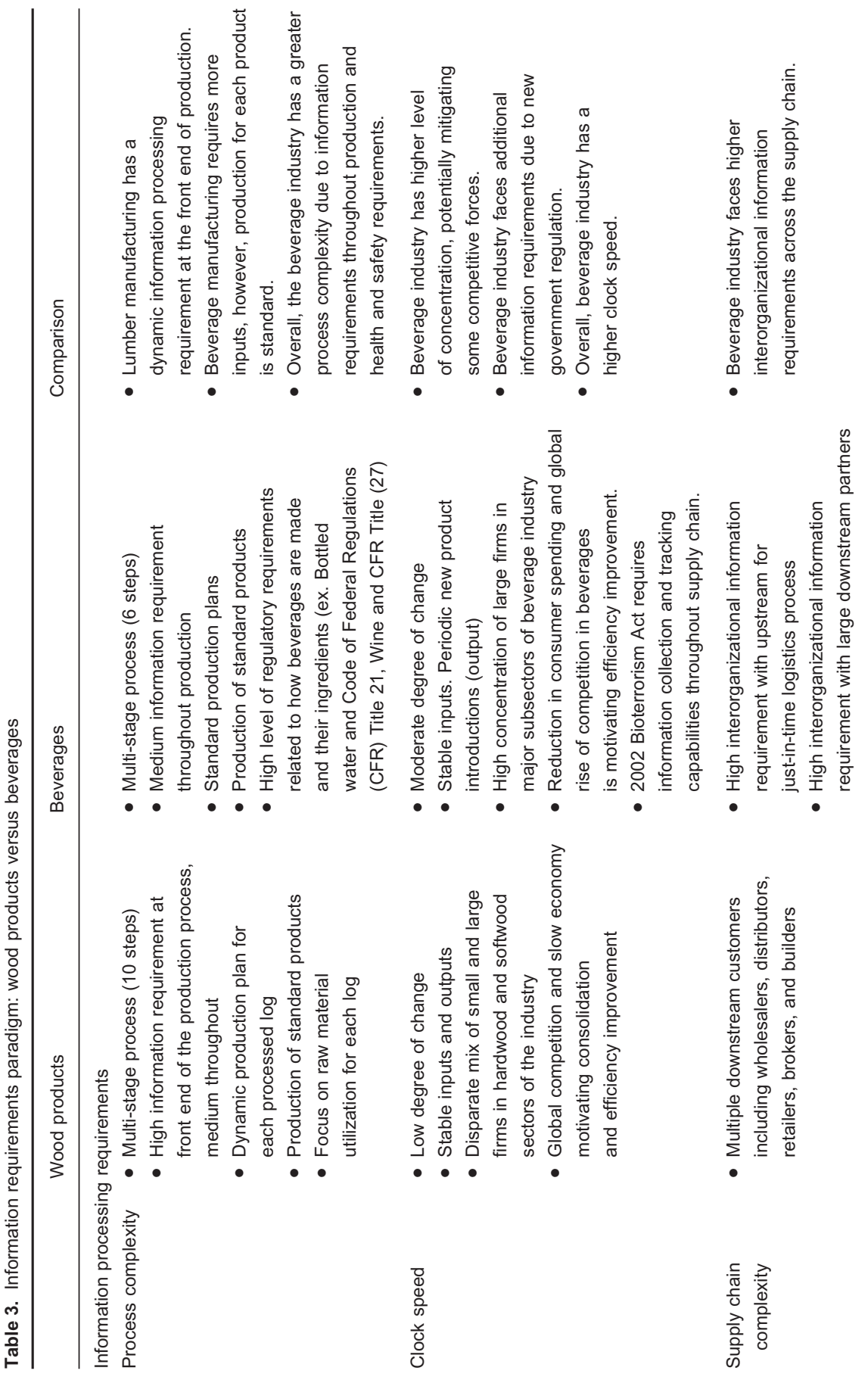




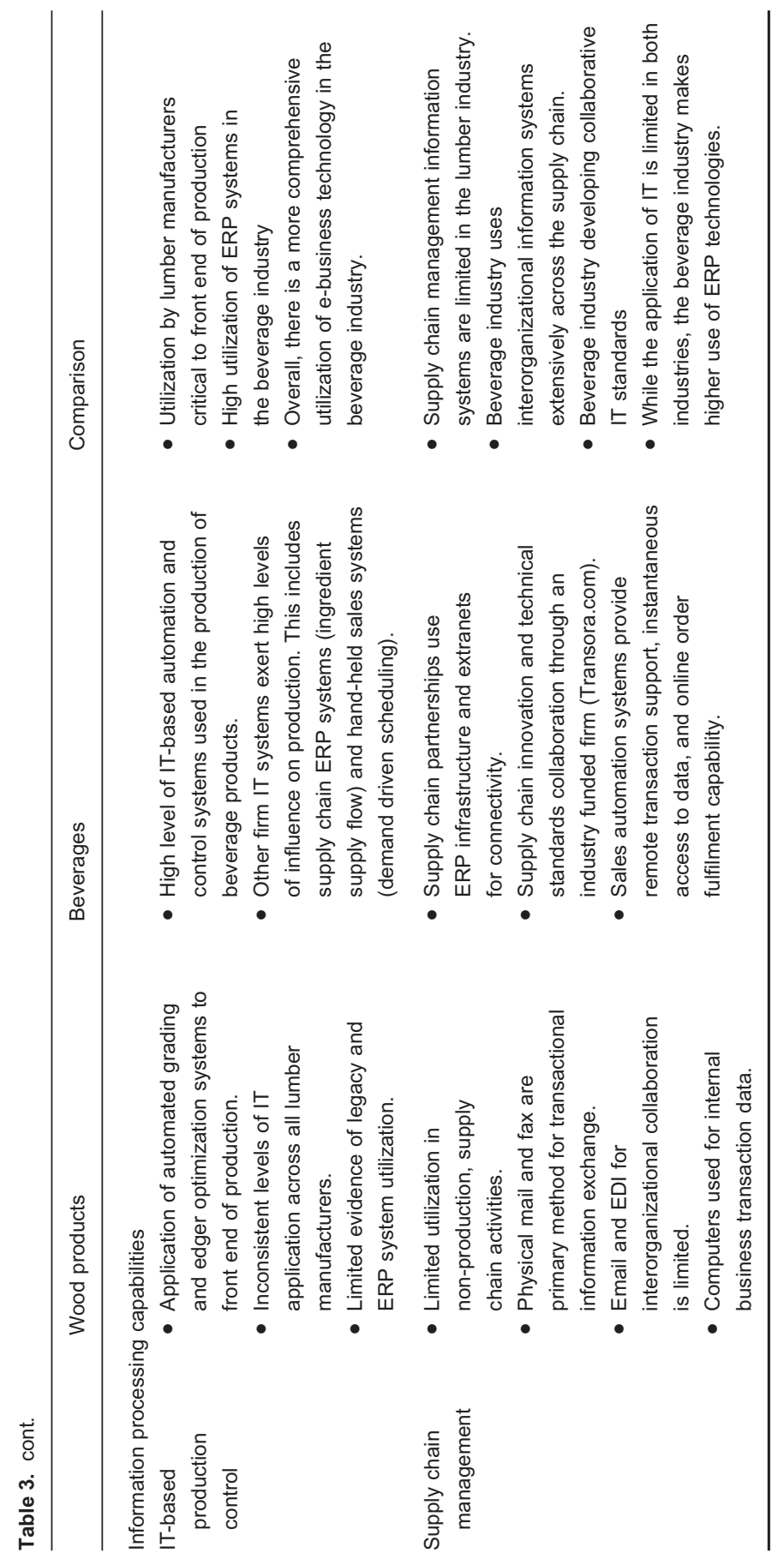

(c) 2007 The Authors Journal compilation @ 2007 Blackwell Publishing Ltd, Information Systems Journal 18, 247-273 
companies have responded by reducing overall production and closing downs mills (Cumbo et al., 2003). Environmental regulations and pressures to achieve sustainable forest development also provide an impetus for change, although it is unclear to what extent this actually impacts the production plans of industry participants. Overall then, the low rate of change in inputs and products and modest degree of competitive pressure create a relatively low-clock speed environment in wood product manufacturing.

\section{- Information processing requirements: supply chain complexity}

The supply chain for wood product manufacturers is more information-intense toward the customer or downstream end (Figure 3). Upstream, timber mills are often located near forests, so that the interface is geographically close. Moreover, from an information perspective, trees take years to mature, meaning that the only source of variation is in the final quality of the logs, which can be monitored for minimal impact on production schedules of timber mills.

There is a greater degree of complexity on the demand side of the supply chain than on the supply side. Wood product manufacturers, for example, sell their products to a host of customers including wholesalers, distributors, retail chains, brokers and builders. This results in a complex web of information exchange as manufacturers conduct multiple transactions with multiple downstream partners (Vlosky et al., 2002). In addition, with regard to their large retail customers, lumber manufacturers face increasing pressure to seamlessly capture and transmit information related to lumber product transactions. This is especially true for companies such as Home Depot that increasingly look to informate and automate the procurement function in order to improve the efficiencies. It is not clear, however, to what extent buyer concentration may provide them with the power to dictate their information processing needs to their suppliers, i.e. wood product manufacturers. The upstream portion of the wood products supply chain is important but because of the low variation of raw timber logs entering the manufacturing process, the information requirements are not as intense as that at the downstream end. The small relative number of raw timber suppliers also reduces the overall information needs of the downstream supply chain.

\section{- Information processing capabilities: IT-based production control}

Certain wood product manufacturers use analytic software extensively to control production within required tolerances. Analytic software is used for scanning and optimization decisions at the front end of lumber production. Edger optimization and automated grading systems help manufacturers produce higher quality products on a more consistent basis (Bowe et al., 2002). However, although efficiency enhancing, analytic systems are not uniformly adopted within the lumber industry. Only $10 \%$ of hardwood manufacturing firms use some sort of advanced scanning and optimizing technology due to the scarcity of resources for these relatively small firms (Bowe et al., 2002), consistent with aggregate industry-level data presented earlier. 


\section{- Information processing capabilities: supply chain management}

Wood product manufacturing firms have made minimal investments in computer networking and interorganizational systems. In a recent survey of primary wood products manufacturers, Vlosky \& Westbrook (2002) find that although a majority of respondents have a web site, not a single one used it for electronic transactions with trading partners. Preferred methods include telephone, mail and fax. Moreover, when internet applications are used, they are used primarily to support financial transactions, such as invoices, order acknowledgements, advanced shipping notices and purchase orders. These are narrow applications that are not integrated with other business functions such as production operations (Vlosky \& Smith, 2003). While computers are being used to enter business transaction information, networking-based applications such as email and EDI are used only sparingly (Vlosky \& Westbrook, 2002).

\section{Beverage manufacturing}

Beverage manufacturers produce non-alcoholic beverages, fermented alcoholic beverages, and distilled alcoholic beverages (Figure $3 b$ ). The major beverage categories are soft drink, bottled water, ice, beer, wine and distilled spirits. As a result of the relatively small size of the distilled spirits market, we focus our discussion on soft drinks, beer and wine products.

\section{- Information processing requirements: process complexity}

The beverage production process comprises six stages: raw materials management, product creation, bottling, packaging, warehousing and distribution. Although various final products are produced, from beer to cola, the primary process difference between beverages occurs in the product creation stage. For example, in soft drinks, syrups are typically mixed with predefined amounts of water and carbon dioxide. In contrast, beer production involves mashing, brewing, fermenting, filtering and aging (Kourtis \& Arvanitoyannis, 2001). To emphasize, other than the product creation stage, beverage manufacturing shares five similar production stages. Raw ingredients are ordered from multiple suppliers and managed in order to minimize inventory cost and protect against stock outs. Beverage products are bottled and put into a variety of package types, with final goods being warehoused and distributed to a multitude of wholesalers and retailers.

Regarding information, the production process is relatively complex. At the raw materials stage, for example, beer manufacturers must analyse the quality of barley, including data on moisture content, nitrogen level and grain weight (Kourtis \& Arvanitoyannis, 2001). In product creation, knowledge and information is required for machine set-up, line processing design, performance measurement and dynamic process improvement to minimize raw material and product loss (Koss, 2003). Production processes must also incorporate regulatory requirements to ensure strict standards are met for each product being created. For example, grape wine production must incorporate regulatory information from the Code of Federal Regulations, Title 27 , which requires producers to limit the addition of dry sugar to no more than $20 \%$ weight, 
of water to no more than $10 \%$ weight of water, and the total alcohol content derived by fermentation of no more than $13 \%$ by volume. (Section 4.21 , The Standards of Identity, Title 27: Alcohol, Tobacco, and Firearms, http://ecfr.gpoaccess.gov/) Similar regulatory requirements exist in bottled water, beer and numerous other beverage products.

Information is also important for warehousing and distribution, as sales order data is processed and interorganizational collaboration with trading partners occurs to minimize product handling and the amount of finished goods inventory maintained in the beverage manufacturing warehouses (Esper \& Williams, 2003). However, despite the amount of information required in beverage manufacturing, the production of beverages is relatively routine. Product recipes are well known and after a production line is set up according to an established design, the creation of a beverage follows a standardized procedure using standard inputs. In summary, given the safety, quality and degradability considerations in this industry, as well as the need for precise tolerances with regard to product and process recipes, production complexity is clearly higher than that of wood products.

\section{Information processing requirements: clock speed}

Similar to wood products, the rate of change in the beverage industry is relatively moderate. Product life cycles are typically quite long, although new brands are introduced regularly (Cioletti, 2003a). Also, input materials - raw ingredients and packaging - as well as fundamental bottling processes do not change rapidly. However, in the realm of competition, beverage production differs substantially from wood product manufacturing. The beverage industry is much more concentrated and contains much larger firms on average. For example, in beer manufacturing, Anheuser-Busch, Miller, and Coors account for over $68 \%$ of 2004 US beer sales (Hemphill, 2005). Coca Cola and Pepsi accounted for $77 \%$ of the 2002-2003 carbonated soft drink sales volume in the USA (Hemphill, 2004). (In wine manufacturing, the top 30 companies account for $90 \%$ of wine market sales. while the top three wine companies - E \& J Gallo, Constellation Brands, and The Wine Group - account for over $60 \%$ of all sales, this sub sector is highly fragmented because of recent growth in the premium wine segment (Wine Business Monthly, 2004).) Such high levels of concentration can reduce overall competition within an industry as firms may find it easier to coordinate their activities and price above market levels (Bain, 1951). While this may result in less of an incentive to innovate, recent research suggests an inverted $U$-shaped relationship between innovation and competition (Aghion et al., 2005).

A second dimension of clock speed that is salient in this industry is regulation. A recent issue within the beverage industry that is raising information needs is the 2002 Bioterroism Act. This regulatory act requires all food and beverage firms to establish the capability to track products from raw ingredients to the end consumer. Beverage firms are applying their resources and capabilities towards capturing information along the beverage supply chain in order to meet this government imposed information requirement (Folwell \& Volanti, 2003; Higgins, 2003a). Overall then, clock speed is moderate in this industry. 


\section{- Information processing requirements: supply chain complexity}

The beverage manufacturing supply chain is information intensive relative to wood products due to upstream and downstream information requirements. Manufacturers that produce soft drink products, for example, must work with multiple suppliers to coordinate shipment of syrups for colas, root beer, fruit drinks and a host of other carbonated beverages. Information must also be shared with suppliers for the procurement and delivery of water, bottles and $\mathrm{CO}_{2}$ gas. On the downstream side, soft drink manufacturers collaborate with distributors, vendors and fountain operation customers. Interorganizational data sharing is a necessity for a seamless logistics process and adds to the overall information requirements of the beverage supply chain.

Also, given the importance of minimizing finished goods inventory, the information shared in the downstream portion of the supply chain is important to beverage manufacturers for product forecasting and production planning processes. Unforeseen delays or miscues in the supply chain can have severely detrimental fiscal impacts as inventory buffers are no longer available to guard against such issues. As an example, inadequate sharing of customer information and production planning led the Coors Corporation to experience product shortfalls during recent high demand seasons such as Christmas and New Year holidays, resulting in lost sales and upset customers (Moozakis, 2001). Another aspect of the supply chain is the concentration in certain downstream customer segments such as grocery stores. This creates buyer power which may act to force beverage producers to adopt IT innovations to better manage downstream physical and logical interfaces. In sum, supply chain complexity is higher than that of wood product manufacturing.

\section{- Information processing capabilities: IT-based production control}

In some beverage product markets, like premium wine and distilled spirits, minimal usage of IT in production is driven primarily by image. For these types of products, the identity of the brand is more important to sales than the unattractive image of computer-driven stainless steel manufacturing (Elliott, 1998). In contrast, analytic technology such as checkweighers, automated metal detectors and quality control software has become important in soft drink and other beverage manufacturing (Higgins, 2002). For example, Coriolis meters are a widely used control technology which incorporates digital processing to control the flow of syrups, juices and other liquid-based beverage ingredients (Higgins, 2003b). Beyond automation and control technology, customer-facing IT solutions also affect the beverage production process. Specifically, soft drink sales personnel use hand-held computers to capture and transmit real-time major customer demand data which is interpreted by production planning systems and translated into more efficient production scheduling (Krell, 2004).

\section{- Information processing capabilities: supply chain management}

A widely used technology in beverage manufacturing supply chain and front end activities is Enterprise Resource Planning (ERP) systems, used for supply chain management and partner 
collaboration (Hayes, 2001). Anheuser Busch uses an SAP module for inventory management of parts for its plant equipment (Fryer, 1998). Workers use the system to obtain part descriptions, quantity available and other pertinent data. Coca Cola also uses an ERP system to integrate with its supply chain partners for best practice information sharing, resource sharing and to capitalize on economies of scale (Violino, 1999).

Networking technology has become an important tool for meeting today's information requirements. Along the supply chain, for example, Coca Cola is undertaking a network-based project to enhance data sharing and synchronization with its upstream suppliers (Foley \& Kontzer, 2004). In the downstream portion of the supply chain, the Coors Corporation has turned to networking technology to integrate distributors with its production planning system. Through enhanced information sharing via an extranet, Coors hopes to eliminate future production shortfalls during high demand seasons (Moozakis, 2001).

In addition to these individual supply chain projects, beverage firms are collaborating to advance supply chain management technology. In this vein, more than 50 of the top consumer product manufacturers have come together to create Transora.com. These producers, which include such beverage manufacturers as Coca Cola and Anheuser-Busch, have helped to start a firm that develops standards-based interorganizational solutions for manufacturing supply chains (Bacheldor, 2000). Central to Transora's services is its standards-based data synchronization network which provides seamless connectivity for collaborative supply chain management. Finally, sales activities appear to be a potentially fruitful area for future networking applications in the beverage industry. In the Annual Food Manufacturers survey, of which beverage manufacturers are a part, respondents indicated that plant data must be instantaneously available to marketing and sales personnel in order to meet today's operational information requirements (Higgins, 2003a). Providing remote connectivity to sales personnel will also allow for streamlined customer fulfilment as sales orders can be instantly recorded (Cioletti, 2003b).

\section{DISCUSSION}

Our analysis has shown systematic patterns that reinforce and refine the information processing perspective applied to IT innovations in general and internet-based innovations in particular. We find a positive association between information processing requirements and internetbased technology usage. Further examination shows that an industry's supply chain structure is a driver of information processing requirements and that the location of information requirements is an important factor in the diffusion of IT innovations, especially internet technologies. Finally, results indicate that regulation can influence internet-based innovation across industries. We now discuss these findings in detail.

First, aggregate descriptive statistics spanning 21 US manufacturing industries show that the use of technologies associated with internet-based innovation tends to be higher in industries with greater information processing requirements. The PC manufacturing industry, which is high in all three dimensions of information processing requirements, is in the top five 
of usage in four of five internet-based innovation technologies and leads in terms of email with trading partners. In contrast, the wood products industry is in the lowest category in all technology usage measures and several innovation dimensions. This finding extends prior understanding of e-commerce adoption antecedents that identified technology competence, firm scope and size, consumer readiness, and competitive pressure as significant determinants (Zhu et al., 2004). By expanding the focus to underlying information processing requirements faced by all firms in an industry, our framework adds a layer of understanding to existing knowledge.

Aggregate descriptive analysis also indicated anomalies, such as the printing industry having the highest percentage of firms adopting internet buying, but the lowest percentage of firms adopting internet selling. This finding shows that although we have focused on three dimensions of information processing requirements, other factors also come into play. Example factors identified in earlier research include market power and the adoption of third-party business-to-business (B2B) portals in textile industries (Cho, 2006) and the potential loss of social capital and the adoption of B2B electronic marketplaces in the beef industry (Driedonks et al., 2005). While our analysis contributes to the overall understanding of industry factors driving internet-based technology adoption, examining the relative importance and potential interrelationships among information processing requirements and other drivers is an interesting avenue of future research.

The second finding is that supply chain structure is an important dimension of information processing requirements, driving enhanced use of internet-based innovations to control the flow of inbound materials and outbound products. Downstream buyers of beverage products include large, national firms such as retail grocery chains. Given the amount of transactions with a few of these large buyers, the beverage industry is sensitive to their needs, and partners to ensure systems integration across the supply chain and smooth flow of product. In contrast to the customers of beverage manufacturing, buyers of wood products are heterogeneous, encompassing wholesalers, distributors, retail brokers and builders. Each buyer has its own particular needs, but none has sufficient purchasing power to drive widespread adoption of sophisticated demand-side electronic integration. This finding sheds new light on the adoption drivers of interorganizational systems such as EDI (Fichman, 2004). Indeed, when combined with earlier evidence (Wigand et al., 2005), our results provide an explanation for minimal adoption of EDI technologies in certain industries: supplier and buyer characteristics. Further research is needed to identify additional aspects of supply chains that drive IT innovation.

The third finding is that the location of information requirements makes a difference with respect to the diffusion of IT innovations, especially internet technologies. For lumber manufacturers, the most intense information requirement occurs at the front end of the production process due to the natural variation in raw timber entering the manufacturing facility. For beverage manufacturers, on the other hand, multiple raw inputs are required to produce alcoholic and non-alcoholic beverages. This imposes a different information requirement vs. lumber manufacturing, as the use of multiple inputs requires information flows to determine and track individual input quality, quantity and the timing of when the input is applied within the 
beverage production process. The nature of procurement, materials and upstream supply industries is thus also an important dimension of information processing requirements that drive IT innovation diffusion.

The fourth finding is that regulation may drive or constrain internet-based innovation across industries. A key difference in information processing requirements between wood and beverage manufacturers arises from a new regulatory act that requires the tracking of beverage products throughout the supply chain. This, in turn, increases the information requirement of beverage manufacturers as they must collect and track data related to its suppliers and manufacturing centres. While our fourth finding is unique to industry-level research on internet technology adoption, it is consistent with existing research examining the adoption of other technologies such as those in the US petroleum refining industry (Chen, 2005).

Overall, our findings indicate that variation in IT adoption and diffusion across industries appears to be due at least in part to industry variation in information processing requirements. This adds to our knowledge of innovation adoption and diffusion phenomena. Limiting the domain of inquiry to factors in the dominant paradigm and extensions would not have yielded such insights. As an example, differences between firms in an industry with medium information processing requirements and those in a low information processing requirements might confound analyses based on firm or technology characteristics, which may lead to insignificant or biased results.

\section{CONCLUSION}

Prior research shows that adopter and technology characteristics affect the extent to which firms adopt technological innovations. Other factors also play a role. We built on prior research to develop a conceptual framework for an information processing requirements paradigm of IT innovation diffusion. To examine the validity of the developed framework, we examined a database of internet-based innovation in the US manufacturing sector. We supplemented this descriptive analysis of aggregate statistics by examining two industries in detail that vary along the three dimensions of information processing requirements: wood product manufacturing and beverage manufacturing.

Results of our study have several implications for research. First, the information requirements paradigm is a useful lens through which to view IT innovation adoption and diffusion and thereby extend the dominant paradigm. By emphasizing the notion of fit between informational needs and processing capabilities afforded by IT, we developed a new perspective on industry phenomena and innovation adoption. This is consistent with Fichman's (2004) call to move beyond the dominant paradigm in IS innovation research. In future research, we plan to build on the foundation developed herein by constructing and validating measures using firm-level data from the US Census Bureau and formally testing the framework developed herein. (Data on more than 35 internet-based innovations in roughly 30000 US manufacturing plants have been collected by the US Census Bureau; a proposal to the US Bureau of the Census, Center for Economic Studies to use these data has been approved.) 
Second, using qualitative industry analysis, we have identified phenomena pertinent to each construct of the framework and salient to particular industry settings. This aids future researchers by demonstrating how higher-level constructs might be operationalized. Third, by examining low-tech, slower-moving industries, we have showed the need to expand the breadth of research focus beyond technological innovators. Examining why innovation is not happening can be as informative as examining why it is. Fourth, as we focused on specific measures of internet-based innovation, such as extranets and EDI, there is a need to examine additional types of IT, such as vendor-managed inventory and collaborative design systems. Finally, a natural extension is to examine two dimensions of difference - traditional firm-level characteristics as well as industry-level phenomena - within the same analysis. This would answer the important question of the extent to which each is important and in what contexts.

An important implication for managers is that although the information processing requirements facing firms within a given industry may show structural uniformity, the response of firms does not. We attempted herein to illustrate the variation in structural patterns of responses across industries. However, there is not always a fit between the two, and in some industries, information capabilities may lag requirements. In such industries, there is great potential to achieve improved productivity and efficiency by leveraging the knowledge of firms in more advanced industries. This is a fruitful area of future research as well as the starting point for managerial application of the developed framework.

Finally, despite our attempts to limit threats to validity, our study suffers from several potential limitations. First, we did not carry out any formal statistical tests due to the aggregate nature of the Census data and lack of other available data sources at present. Other factors might be at work, such as the size of firms, the degree to which the industry is concentrated, the path-dependent nature of innovation, and the like. Moreover, standard measures of reliability and validity could not be calculated because of the limited nature of the data. Another potential limitation is that we were not able to incorporate within-industry variation in both information requirements and capabilities. Our data are cross-sectional, so we were not able to study the dynamic nature of industries over time. Specifically, information processing requirements may not be stable over time, and their evolution would also likely affect the evolution of technology adoption and diffusion. (We thank an anonymous reviewer for underscoring this point.) Our descriptive approach to applying the framework to US industry data must therefore be interpreted with caution. Also, the model does not incorporate all the factors driving a firm's IT application in production or in its supply chain. Application of the framework to the wood product and beverage manufacturing industries was based on secondary data, which may suffer from inaccuracies. Also, it is difficult to estimate the degree to which findings based on these two industries may generalize to others. Given our examination of several other industries in selecting these two, as well as careful analysis of prior research of high-tech, high-clock speed industries, it is our preliminary belief that findings will generalize. At the least, systematic patterns in quantitative and qualitative data showed herein point to the need for more detailed examination of these issues. Despite these limitations, then, the structural consistency in our findings across the two methods provides a sound conceptual point of departure for future research. 


\section{REFERENCES}

Aghion, P., Blundell, R., Griffith, R. \& Howitt, P. (2005) Competition and innovation: an inverted-u relationship. Quarterly Journal of Economics, 120, 701-728.

Anandarajan, M. \& Arinze, B. (1998) Matching client/server processing architectures with information processing requirements: a contingency study. Information and Management, 34, 265-274.

Araman, P., Schmoldt, D., Cho, T.-H., Zhu, D., Conners, R. \& Kline, D. (1992) Machine vision systems for processing hardwood lumber and logs. Al Applications, 6, 13-26.

Bacheldor, B. (2000) IT: always in good taste. Information Week, 803, 237-242.

Bain, J. (1951) Relation of profit rate to industry concentration: American manufacturing, 1936-1940. Quarterly Journal of Economics, 65, 293-324.

Bensaou, M. \& Venkatraman, N. (1995) Configurations of interorganizational relationships: a comparison between U.S. and Japanese automakers. Management Science, 41, 1471-1492.

Bowe, S., Smith, R., Kline, D. \& Araman, P. (2002) A segmental analysis of current and future scanning and optimizing technology in the hardwood sawmill industry. Forest Products Journal, 52, 68-76.

Brancheau, J.C. \& Wetherbe, J.C. (1990) The adoption of spreadsheet software: testing innovation diffusion theory in the context of end-user computing. Information Systems Research, 1, 115-143.

Cagliano, R., Caniato, F. \& Spina, G. (2003) E-business strategy. International Journal of Operations and Production Management, 23, 1142-1162.

Chen, M. (2005) Technology adoption in response to changes in market conditions: evidence from the US petroleum refining industry. Economics of Innovation and New Technology, 14, 735-756.

Chiasson, M. \& Davidson, E. (2005) Taking industry seriously in information systems research. Information Systems Research, 29, 591-606.

Cho, V. (2006) Factors in the adoption of third-party B2B portals in the textile industry. Journal of Computing Information Systems, 46, 18-31.

Chwelos, P., Benbasat, I. \& Dexter, A.S. (2001) Research report: empirical test of an EDI adoption model. Information Systems Research, 12, 304-321.

Cioletti, J. (2003a) And now for something completely different. Beverage World, 122, 49-50.

Cioletti, J. (2003b) The paperless route. Beverage World, 122, 82.
Cooper, R.B. \& Zmud, R.W. (1992) Information technology implementation research: a technological diffusion approach. Management Science, 36, 123-139.

Crowston, K. \& Myers, M.D. (2004) Information technology and the transformation of industries: three research perspectives. Journal of Strategic Information Systems, 13, 5-28.

Cumbo, D., Smith, R. \& Araman, P. (2003) Low-grade hardwood lumber production, markets, and issues. Forest Products Journal, 53, 17-24.

Driedonks, C., Gregor, S., Wassenaar, A. \& van Heck, E. (2005) Economic and social analysis of the adoption of B2B electronic marketplaces: a case study in the Australian beef industry. International Journal of Electronic Commerce, 9, 49-72.

Elliott, C. (1998) A loaf of bread, a jug of wine, a notebook computer. Journal of Business Strategy, 19, 34-38.

Esper, T. \& Williams, L. (2003) The value of collaborative transportation management (CTM): its relationship to CPFR and information technology. Transportation Journal, 42, 55-65.

Fichman, R.G. (2004) Going beyond the dominant paradigm for information technology innovation research: emerging concepts and methods. Journal of the Association for Information Systems, 5, 314-355.

Fine, C. (1998) Clockspeed: Winning Industry Control in the Age of Temporary Advantage. Perseus Books, Reading, MA, USA.

Fine, C.H. (2000) The clockspeed chronicles. Supply Chain Management Review, 4, 60-64.

Foley, J. \& Kontzer, T. (2004) Coca-Cola plans to refresh its supply chain. Information Week, 976, 22.

Folwell, R. \& Volanti, M. (2003) The changing market structure of the USA wine industry. Journal of Wine Research, 14, 25-30.

Forza, C., Romano, P. \& Vinelli, A. (2000) Information technology for managing the textile apparel chain: current use, shortcomings and development directions. International Journal of Logistics: Research and Applications, 3, 227-243.

Fowler, S., Novack, A.-M. \& Stillings, M. (2000) The evolution of a manufacturing web site. Computer Networks, 33, 365-376.

Fryer, B. (1998) Enterprise apps: best investment? Information Week, 700, 159-162.

Galbraith, J.R. (1977) Organization Design. AddisonWesley, Reading, MA, USA. 
Hayes, M. (2001) IT moves to the front burner. Information Week, 855, 133-135.

Hemphill, G.A. (2004) US Soft Drink Sales Flat in 2003. Beverage Marketing Corporation Report, New York, 4 March.

Hemphill, G.A. (2005) US Beer Market Struggles to Grow in 2004. Beverage Marketing Corporation Report, New York, 17 May.

Higgins, K. (2002) Double duty inspection tools. Food Engineering, 74, 61-65.

Higgins, K. (2003a) The state of food manufacturing. Food Engineering, 75, 50-56.

Higgins, K. (2003b) Better products through better control. Food Engineering, 75, 37-39.

Jarvis, C., Mackenzie, S. \& Podsakoff, P. (2003) A critical review of construct indicators and measurement model misspecification in marketing and consumer research. Journal of Consumer Research, 30, 199-218.

Johnson, M.E. \& Whang, S. (2002) E-business and supply chain management: an overview and framework. Production and Operations Management, 11, 413423.

Karimi, J., Somers, T.M. \& Gupta, Y. (2004) Impact of environmental uncertainty and task characteristics on user satisfaction with data. Information Systems Research, 15, 175-193.

King, J., Gurbaxani, V., Kraemer, K., McFarlan, F., Raman, K. \& Yap, C. (1994) Institutional factors in information technology innovation. Information Systems Research, 5, 139-169.

Koppel, N. (2004) Panel upholds US tariffs on Canadian lumber. Portland Press Herald.

Koss, P. (2003) IT concepts in beverage operations. Beverage World, 122, 61.

Kourtis, L. \& Arvanitoyannis, I. (2001) Implementation of hazard analysis critical control point (HACCP) system to the alcohol beverages industry. Food Reviews International, 17, 1-44.

Kraemer, K. \& Dedrick, J. (2002) Strategic use of the internet and e-commerce: Cisco Systems. Journal of Strategic Information Systems, 11, 5-29.

Kraemer, K., Dedrick, J. \& Yamashiro, S. (2000) Refining and extending the business model with information technology: Dell Computer Corporation. The Information Society, 16, 5-21.

Krell, E. (2004) Enabling technology to enable. Review, 21, 28-31.

Loh, L. \& Venkatraman, N. (1992) Diffusion of information technology outsourcing: influence sources and the Kodak effect. Information Systems Research, 3, 334-358.
Lyytinen, K. \& Rose, G. (2003) Disruptive information system innovation: the case of internet computing. Information Systems Journal, 13, 301-330.

Macher, J., Mowery, D. \& Simcoe, T. (2002) e-Business and disintegration of the semiconductor industry value chain. Industry and Innovation, 9, 155-181.

March, J. \& Simon, H. (1958) Organizations. John Wiley \& Sons, New York, NY, USA.

Mendelson, H. \& Pillai, R.R. (1998) Clockspeed and informational response: evidence from the information technology industry. Information Systems Research, 9, 415-433.

Mendelson, H. \& Pillai, R.R. (1999) Industry clockspeed: measurement and operational implications. Manufacturing and Service Operations Management, 1, $1-20$.

Moozakis, C. (2001) Coors looks for a silver bullet. Internet Week, 870, 14-15.

Mustonen-Ollila, E. \& Lyytinen, K. (2003) Why organizations adopt information system process innovations: a longitudinal study using Diffusion of Innovation theory. Information Systems Journal, 13, 275-297.

Phan, D.D. (2003) E-business development for competitive advantages: a case study. Information and Management, 40, 581-590.

Prasad, B. (1998) Designing products for variety and how to manage complexity. Journal of Product and Brand Management, 7, 208-222.

Rogers, E.M. (1983) Diffusion of Innovations. Free Press, New York, NY, USA.

Swanson, E.B. (1994) Information systems innovation among organizations. Management Science, 40, 10691092.

Swanson, L. (2003) An information-processing model of maintenance management. International Journal of Production Economics, 83, 45-64.

Tehan, R. (2003) E-Commerce Statistics: Explanation and Sources, RL31293, pp. 1-12. Congressional Research Service Documents, Information Research Division, The Library of Congress, Washington, DC, USA.

Teng, S. \& Jaramillo, H. (2005) A model for evaluation and selection of suppliers in global textile and apparel supply chains. International Journal of Physical Distribution and Logistics Management, 35, 503-523.

Tornatzky, L.G. \& Fleischer, M. (1990) The Process of Technology Innovation. Lexington Books, Lexington, MA, USA.

Tushman, M.L. \& Nadler, D.A. (1978) Information processing as an integrating concept in organizationaldesign. Academy of Management Review, 3, 613-624. 
Van de Ven, A.H. \& Ferry, D.L. (1980) Measuring and Assessing Organizations. Wiley, New York, NY, USA.

Violino, B. (1999) Extended enterprise. Information Week, 726, 46-53.

Vlosky, R. \& Smith, T. (2003) eBusiness in the U.S. hardwood lumber industry. Forest Products Journal, 53, 21-29.

Vlosky, R. \& Westbrook, T. (2002) E-business exchange between home buyers and wood products suppliers. Forest Products Journal, 52, 38-43.

Vlosky, R., Westbrook, T. \& Poku, K. (2002) An exploratory study of internet adoption by primary wood products manufacturers in the western United States. Forest Products Journal, 52, 35-42.

Wang, E.T. (2003) Effect of fit between information processing requirements and capacity on organizational performance. International Journal of Information Management, 23, 239-247.

Wigand, R., Steinfeld, C. \& Markus, M.L. (2005) Information technology standards choices and industry structure outcomes: the case of the U.S. home mortgage industry. Journal of Management Information Systems, 22, 165191.

Wine Business Monthly (2004) The top 30 U.S. wine companies. [WWW document.] URL http://winebusiness. com/specialsection/Top30USWineCompanies.cfm (last accessed 21 May 2004).

Woodward, J. (1994) Industrial Organization: Theory and Practice. Oxford University Press, London, UK.

Zhu, K., Kraemer, K.L., Xu, S. \& Dedrick, J. (2004) Information technology payoff in e-business environments: an international perspective on value creation of e-business in the financial services industry. Journal of Management Information Systems, 21, 17-54.
Zmud, R. \& Apple, L.E. (1992) Measuring technology incorporation/infusion. Journal of Product Innovation Management, 9, 148-155.

\section{Biographies}

Nigel P. Melville is an Assistant Professor of Business Information Technology at the Stephen M. Ross School of Business, University of Michigan. His research focuses on the economic impact of information technology and digital commons problems. Professor Melville's articles appear in Information Systems Research, MIS Quarterly, Communications of the ACM, and International Journal of Electronic Commerce. $\mathrm{He}$ is an Editor of the volume Global E-Commerce: Impacts of National Environment and Policy (Cambridge University Press). Professor Melville holds a BS in Electrical Engineering from UCLA, an MS in Electrical and Computer Engineering from UC Santa Barbara, and a PhD in Management from UC Irvine.

Ronald Ramirez is an Assistant Professor at the Business School, University of Colorado at Denver. His research focuses on the economic value of information technology to organizations and industries. Ron holds a Ph.D. in Management from the Paul Merage School of Business, University of California, Irvine. He earned a Master of Business Administration at the Marshall School of Business, University of Southern California, and a Bachelor of Science in Electrical Engineering from California State University, Fresno. Before earning his $\mathrm{PhD}$, Ron worked in the areas of finance, operations and information technology at AT\&T, VLSI Technologies and the Chevron Corporation. 